\title{
The First Stage of Acquired Syndactyly Reconstruction - A Rare Case Report
}

\section{Lucretya Yeniwati Tanuwijaya ${ }^{1}$, Agus Roy Rusly Hariantana Hamid ${ }^{2}$, I Gusti Putu Hendra Sanjaya ${ }^{3}$, I Made Suka Adnyana ${ }^{4}$}

${ }^{1-4}$ Division of Plastic Reconstructive and Aesthetic Surgery, Department of Surgery,
Faculty of Medicine Udayana University / Sanglah General Hospital Bali, Indonesia.

Corresponding Author: Lucretya Yeniwati Tanuwijaya

DOI: https://doi.org/10.52403/ijhsr.20220112

\begin{abstract}
Background: Acquired syndactyly is a very rare disorder on the interdigital area. Syndactyly with only soft tissue involvement can be a sequela of trauma, such as burn, inflammation or infection in the interdigital area, resulting in bony fusion following crush injury.

Case Report: An 8-year-old boy came to our department with fusion from the base to the tip of the first to fourth right toes since the accidental step on burnt plastic 5 years ago. He complained of a poor appearance and discomfort when walking. Then we performed zigzag incision for first to second toes and third to fourth toes. Skin graft closure was performed to cover the defect on third to fourth toes. The second reconstruction surgery will be scheduled 6 months later.

Discussion: The surgical techniques for foot syndactyly were derived from those for hand syndactyly, which are to separate the digital fusion by creating local skin flap. Additionally, skin graft might be necessary when recent surgeons avoid the use of skin graft for open treatment, primary closure by defatting, or intricate local flaps. These can shorten the operation time and minimize donor site morbidity. However, surgeons should consider the free tension closure of the wound by combining the skin graft after the flap.

Conclusion: Reconstruction procedure for foot syndactyly aims to improve the appearance and function of the toes as well as to avoid progressive deformity through development. The skin graft addition in combination of skin flap shows promising outcome.
\end{abstract}

Keywords: acquired syndactyly, syndactyly reconstruction, zigzag flap, skin graft

\section{BACKGROUND}

Syndactyly of the hand or foot is a common congenital limb malformation with an incidence of approximately 1 in every 2,000 to 2,500 cases. $^{1,2}$ As reported in America in 1980, isolated syndactyly has been observed in 2.2/10,000 livebirths, with isolated foot syndactyly occurring 4 times more frequently than isolated hand syndactyly. ${ }^{2}$ In East Asia were reported only 118 patients with foot syndactyly from 1990 to 2014 by Kim and colleges. ${ }^{3}$ Unfortunately, there was no demographic data of foot syndactyly in Indonesia. Foot syndactyly has been less frequently discussed than hand syndactyly, despite its higher incidence. It is characterized by fusion variations of the skin and/or bone of adjacent digits, leading to reduced or absent movement. ${ }^{3,4}$ Syndactyly may be classified into complete (extending through the fingertips with nail involvement), incomplete (webbing only partially along the length of the digit), simple (soft tissue involvement only), complex (bony or joint fusion), or complicated (multiple involved tissues including bones, joints, tendons, muscles, or neurovascular bundles). 
Syndactyly is not always the result of congenital abnormalities. Syndactyly could be acquired from trauma, such as burn, or inflammation, or infection in the interdigital area. Full syndactyly with bony fusion can occur following crush injury as the cause of severe trauma.,6,7 We report this case because it is a rare case and there is no standard algorithm in dealing with acquired syndactyly, especially on the toes.

\section{CASE REPORT}

An 8-year-old boy came to our department complained of a poor appearance and discomfort in walking. His right foot accidentally stepped on burnt plastic 5 years ago when he played with his friend in the yard. Then he got medical care from a midwife in his village with sterile gauze unregularly. After 3 months, the wound healed with fusion from the base to the tip of the first to fourth right toes. The patient undergone $\mathrm{x}$-ray examination to diagnose the syndactyly. The technique of this surgery used zigzag incision for first to second toes and third to fourth toes. Then skin graft closure was performed to cover the defect on third to fourth toes. The skin graft was taken from medial plantar region to avoid the pain sensation which could give any difficulty on foot step motion. One week postoperative evaluation showed satisfactory appearance and free tension wound on all flap and skin graft. Two months postoperative evaluation showed a fully healed wound with no tension scar. Then the second reconstruction surgery will be scheduled 6 months after the first surgery.
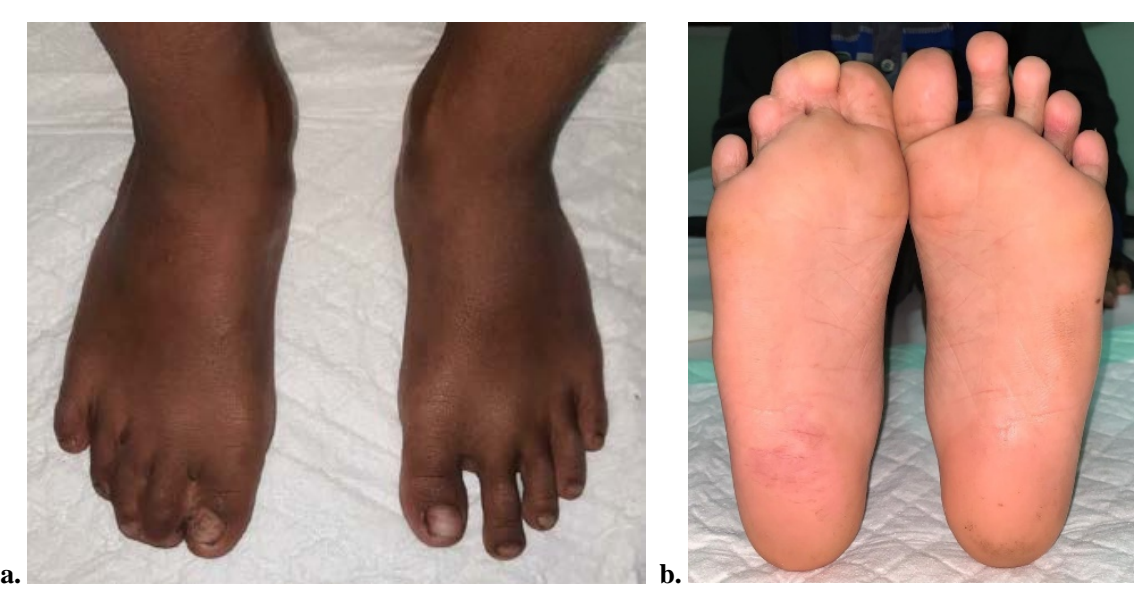

Picture 1. Syndactyly was observed on first to fourth right toes. (a) The dorsal appearance. (b) The plantar appearance.

b.

Picture 2. The $x$-ray of right and left foot showed simple incomplete syndactyly of first to fourth right toes. (a) The anteroposterior view. (b) The oblique view. 

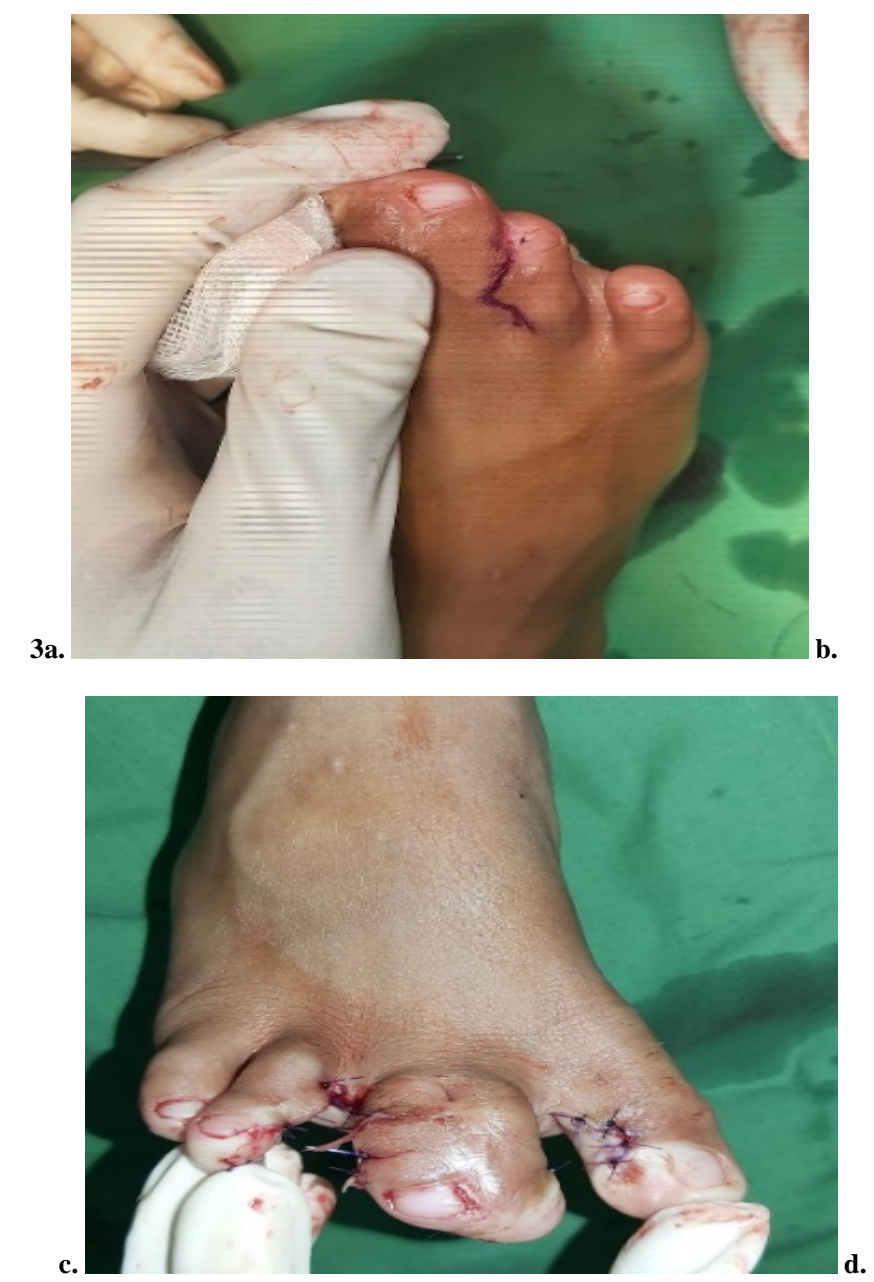

Picture 3. (a) The flap design of syndactyly separation. (b) The skin graft was taken from medial plantar region of right foot to avoid the walking motion. (c) The upper appearance right after the separation. (d) The lower appearance of the right foot.

\section{DISCUSSION}

Acquired syndactyly is a very rare disorder on the interdigital area. Syndactyly can be a sequela of trauma such as burn, inflammation of infection to the interdigital area as reported by Kim and colleges and Kirkup and colleges, when bony fusion can occur following crush injury., ${ }^{5,6,7}$ Loss of interdigital epidermal surface allowed healing with fusion of the adjacent tissues. However, it is difficult to perform flaps or grafts on interdigital areas between toes and the procedure usually requires hospitalization. ${ }^{5}$ 
The anatomy and surgical landmarks of hand and foot web spaces are different. A flap design for foot web space reconstruction using the same ratio as the hand web space may not fully cover the foot web space. As a result, a skin graft may be needed to cover the bare area or sutures in the middle of the web space and lead to "web creep," which is secondary scarring inside web spaces that causes pain, limits toe and foot motion, and has poor cosmetic outcomes. ${ }^{7,8,9}$ Luangjarmekorn and colleges hypothesize that foot and hand web spaces have different anatomical dimensions and need specific flap designs for web space reconstruction in each region. Most of the toe syndactyly cases need flap lengths of nearly the entire proximal phalangeal length (approximately $80 \%$ to $90 \%$ of the proximal phalangeal length). ${ }^{9,10}$

Reconstruction procedure for foot syndactyly aims to improve the appearance and function of the toes as well as to avoid progressive deformity through development. 4,7-12 The surgical methods used for foot syndactyly were derived from those for hand syndactyly.,4 Conventional surgical treatment for syndactyly is performed using various plastic surgery techniques, which consist of division and reconstruction with a dorsal skin flap and a skin graft to cover the raw surface. ${ }^{3,4,7,8}$ The problems with this treatment include trophic alterations in the transferred flaps and trauma in the donor area. The surgical treatment may vary according to the type of syndactyly, i.e. whether it is simple or complex, and also whether it is partial or complete. The results vary as a function of greater or lesser complexity of the syndactyly. They are worse when bone structural alterations are present. $^{7}$

Recently, various techniques that do not require the application of skin grafts, such as open treatment, primary closure by defatting or intricate local flaps have been reported. ${ }^{3,7}$ The graft-free method includes variations of the island flap technique, in which the newly created commissure is reconstructed with island flaps, and the lateral open aspects of the toes are closed primarily with interdigital skin flaps. ${ }^{4,7}$ These techniques are advantageous in that they shorten the operation time and minimize donor site morbidity. However, these techniques, despite their advantages, are associated with increased risks of sensory deficit due to excessive subcutaneous fat removal for primary closure, wound dehiscence following extensive tension, and secondary complications, such as web creep, flexion contracture, and angulation deformity. ${ }^{3,4}$

Saito and colleges documented case series using flap technique which required switched the axis of the traditional rectangular flap from the longitudinal to the transverse direction from the dorsum skin of proximal toe to be redirected $90^{\circ}$ to be inset into the commissure. However, lateral resurfacing was still performed using both interdigitating flaps and skin grafts to prevent the web creep. ${ }^{8}$

When tension-free closure is performed, it is important to choose donor from an area that has a lack of hair growth, as this could lead to an undesirable cosmetic result. Skin grafts can be obtained from the hypothenar eminence, instep of the foot, wrist, cubital fossa, or groin to fill the defects. In complex cases closing wedge, osteotomies may be indicated to correct for angulation differences. Collateral ligament integrity should be tested intraoperatively to determine if advancement or reconstruction is indicated. ${ }^{4,11,12}$

\section{CONCLUSION}

The goal of the treatment for children with syndactyly is surgical and its aims are to improve the appearance and function of the toes and to avoid progressive deformity in the developing human being. However, surgeons should consider the free tension closure by combining skin graft as addition to skin flap.

\section{Acknowledgement: None}

\section{Conflict of Interest: None}




\section{Source of Funding: None}

\section{REFERENCES}

1. Grabb W, Smith J, Chung K. Grabb and Smith's plastic surgery. Philadelphia, Pa: Wolters Kluwer; 2020.

2. Castilla EE, Paz JE, Orioli-Parreiras IM. Syndactyly: Frequency of specific types. American Journal of Medical Genetics. 1980;5(4):357-364.

3. Kim J, Kim B, Kwon S. Foot Syndactyly: A Clinical and Demographic Analysis. Archives of Plastic Surgery. 2016;43(6): 559-563.

4. Hinkley J, Fallahi A. Syndactyly. ncbi.nlm.nih.gov. 2021 [cited 29 March 2021]. Available from: https://www.ncbi.nlm.nih.gov/books/NBK5 57704/

5. Kirkup M, Lovell C. Acquired syndactyly secondary to acrodermatitis continua of Hallopeau. British Journal of Dermatology. 2005;152(5):1083-1084.

6. Kim S, Sun Y, Yoon T, Kim T. Treatment of acquired syndactyly by gauze-fixed epidermal graft after radiosurgery. International Journal of Dermatology. 2003;42(10):832-833.

7. Cortez M, Fernandes Júnior J, da Silva R, Gilbert A, Valenti P, Brandt C et al. Surgical results from treating children with syndactyly through the collective effort system at "SOS Hand Recife" between 2005 and 2009. Revista Brasileira de Ortopedia (English Edition). 2014;49(4):396-400.
8. Saito S, Suzuki Y, Suzuki S. Technique of Dorsal Transversely Oriented Transposition Flap for Web Reconstruction in Toe Syndactyly Surgery. The Journal of Foot and Ankle Surgery. 2015;54(6):1119-1123.

9. Luangjarmekorn P, Kulrat P, Honsawek S, Kitidumrongsook P. Anatomical Differences Between Foot and Hand Web Space Reconstruction. The Journal of Foot and Ankle Surgery. 2020;59(1):31-37.

10. Nash W, Walker R, Patel R, Singh S. A Simple Alternative Treatment for Syndactyly of the Toe. The Journal of Foot and Ankle Surgery. 2016;55(5):1024-1026.

11. Bouvet C, Balagué N, Modarressi A, Beaulieu J. Management of postburn hand scar contractures | East and Central African Journal of Surgery [Internet]. Journal.cosecsa.org. 2021 [cited 29 March 2021]. Available from: https://journal.cosecsa.org/index.php/ECAJ S/article/view/20190057/1679

12. Vekris M, Lykissas $M$, Soucacos $P$, Korompilias A, Beris A. Congenital Syndactyly: Outcome of Surgical Treatment in 131 Webs. Techniques in Hand \& Upper Extremity Surgery. 2010;14(1):2-7.

How to cite this article: Lucretya Yeniwati Tanuwijaya, Agus Roy Rusly Hariantana Hamid, I Gusti Putu Hendra Sanjaya et.al. The first stage of acquired syndactyly reconstruction - a rare case report. Int J Health Sci Res. 2022; 12(1): 87-91. DOI: https://doi.org/10.52403/ ijhsr.20220112 